\title{
Influência da irrigação no crescimento de mudas de Schinus terebinthifolius
}

\author{
Weslley Wilker Corrêa Morais ${ }^{1}$, Felipe Susin², Magnos Alan Vivian³, Maristela Machado Araújo² \\ ${ }^{1}$ Universidade Estadual de Roraima, Rodovia 210, Km 70, CEP 69375-000, São João da Baliza, RR, Brasil \\ 2 Universidade Federal de Santa Maria, Avenida Roraima, n 1000, CEP 97105-900, Santa Maria, RS, Brasil \\ ${ }^{3}$ Escola Superior de Agricultura "Luiz de Queiroz", Universidade de São Paulo, Av. Pádua Dias, 11, CEP 13418-900, Piracicaba, SP, Brasil
}

\section{"Autor correspondente: \\ weslley_eng@yahoo.com.br \\ Termos para indexação: \\ Aroeira vermelha \\ Lâmina d'água \\ Características morfológicas}

Index terms:

Aroeira vermelha

Water depth

Morphologic features

Histórico do artigo:

Recebido em 15 ago 2011

Aprovado em $20 \mathrm{dez} 2011$

Publicado em 30 mar 2012
Resumo - O objetivo foi avaliar o desenvolvimento de mudas de Schinus terebinthifolius em diferentes lâminas de irrigação efetiva. O experimento foi instalado na casa de vegetação do viveiro florestal do Departamento de Ciências Florestais da Universidade Federal de Santa Maria. O delineamento utilizado foi o de blocos ao acaso consistindo em quatro tratamentos, com três blocos. Os tratamentos avaliados foram 8, 10, 12 e 14 mm de água diária, respectivamente T1, T2, T3 e T4. A produção das mudas foi realizada em tubetes de $280 \mathrm{~cm}^{3}$, preenchidos com substrato, composto a base de casca de Pinus e fertilizante. A avaliação do crescimento das mudas foi realizada através das seguintes características: altura da parte aérea (APA), diâmetro do colo (D), massa seca de raiz (MSR), massa seca da parte aérea (MSPA), massa seca total (MST) e relação APA/D. O tratamento T3 apresentou o melhor desempenho em relação às características avaliadas, seguido do T2. Assim, pode-se inferir que a produção de mudas de Schinus terebenthifolius necessita de uma lâmina de água diária em torno de $10 \mathrm{~mm}$, a qual é menor do que a necessária para outras espécies pioneiras.

\section{Influence of the irrigation in the growth Schinus terebinthifolius seedlings}

\begin{abstract}
Aiming to evaluate the development of seedlings of Schinus terebinthifolius under different irrigation depth, an experiment was installed in a greenhouse. The experimental design used was randomized block consisting of 4 treatments with 3 blocks. The irrigation depths evaluated were 8, 10, 12 and $14 \mathrm{~mm}$ daily, respectively T1, T2, T3 and T4. Seedling production was performed in tubes with $280 \mathrm{~cm}^{3}$ filled with pine bark basis substrate and fertilizer. The development of the seedlings, were evaluated by the following characteristics: height of aerial part (APA), diameter at breast height (D),dried mass weight of roots (PMSR), dried mass weight of aerial part (PMSPA), total dried mass (MST) and relation (h/d). The treatment T3 presented the best results in relation to the appraised variables, followed by T2. The Schinus terebenthifolius needs a daily sheet of water of around $10 \mathrm{~mm}$, which is smaller than other pioneer species.
\end{abstract}




\section{Introdução}

Nos últimos anos, os recursos florestais envolvendo espécies arbóreas nativas vêm sendo amplamente explorados, gerando divisas e riquezas para o país. Entretanto, ao longo desse período, poucos plantios foram conduzidos com espécies nativas. Mesmo nos anos 80, com o incentivo florestal, os plantios foram direcionados para espécies exóticas, principalmente as do gênero Pinus e Eucalyptus, enquanto as espécies florestais nativas continuaram sendo exploradas de forma não sustentável.

A utilização das espécies nativas em plantios tem esbarrado em vários problemas técnicos, destacandose os relacionados com a falta de conhecimento autoecológico, a irregularidade de crescimento e a escolha de métodos silviculturais adequados. A ausência de difusão dos conhecimentos existentes faz com que muitas espécies florestais valiosas, entre elas a aroeiravermelha, sejam subutilizadas.

A aroeira-vermelha (Schinus terebinthifolius Raddi), também conhecida como aroeira, aroeira-pimenteira ou fruto-de-sabiá, ocorre desde o Rio Grande do Sul até Pernambuco. A espécie é recomendada, por Lorenzi (1992), para recuperação de áreas degradadas e marginais, devido ao seu caráter de pioneirismo e agressividade, e por ser zoocórica, ou seja, dispersão realizada por animais.

$\mathrm{Na}$ silvicultura, assim como na maioria das atividades agrárias, é necessário o uso da água em todas as fases do processo produtivo, necessitando de tecnologia que otimize o seu uso, considerando a preocupação ambiental e legal. Atualmente, no Brasil, antes de iniciar a construção de sistemas de irrigação, a legislação amparada na lei $\mathrm{N}^{\circ} 6.381$, de 2005 prevê que os produtores consultem as prefeituras locais, para verificar se existem restrições ao uso de água para irrigação. Dependendo da região, obter uma autorização pode ser muito difícil ou até impossível.

No Brasil, o sistema de irrigação de viveiros mais usual é a microaspersão, sistema que gera desperdícios em razão de fatores como vento, espaços vazios e má distribuição dos aspersores em relação às mudas (Augusto et al., 2007). A irrigação é uma das etapas mais importantes durante a produção de mudas em viveiro, devido a sua influência direta na qualidade das mudas. Em relação à produção de mudas, a quantificação da necessidade hídrica na sua formação é extremamente importante, pois a falta ou excesso pode limitar o seu crescimento e desenvolvimento. A falta de água acarreta o estresse hídrico, além da diminuição na absorção de nutrientes. $\mathrm{O}$ excesso pode favorecer a lixiviação dos nutrientes e também proporcionar um microclima favorável ao desenvolvimento de doenças, além das questões socioambientais relativas à economia de água e ao acúmulo de lixiviados no solo (Lopes et al., 2007).

Neste contexto, o objetivo foi avaliar o efeito de diferentes lâminas efetivas de irrigação sobre o crescimento de mudas de aroeira-vermelha.

\section{Material e métodos}

O experimento foi instalado em casa de vegetação, no Viveiro Florestal da Universidade Federal de Santa Maria, no período de 17 de agosto a 17 de dezembro de 2008, com temperatura e umidade diárias monitoradas com termômetro bulbo seco e úmido, desde o início da semeadura até final do experimento (Figura 1).

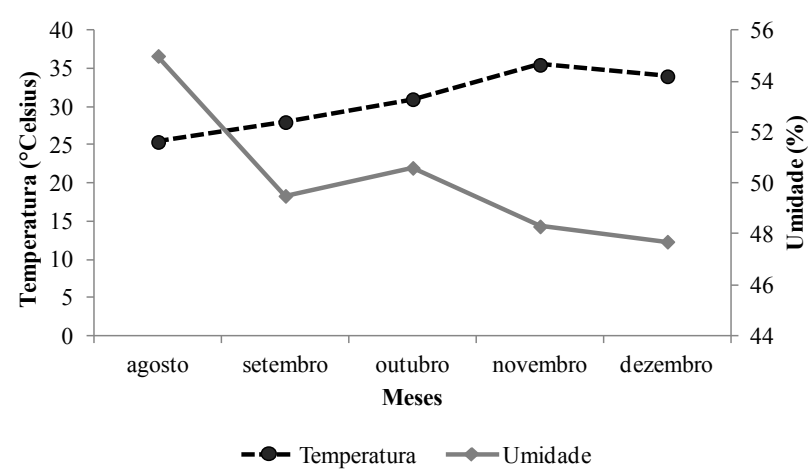

Figura 1. Temperaturas e umidade média mensal dentro da casa de vegetação durante a realização do experimento.

As sementes de Schinus terebinthifolius (aroeiravermelha) utilizadas para a produção das mudas foram provenientes do convênio Universidade Federal de Santa Maria/Associação de Fumicultores do Brasil (UFSM/ AFUBRA) coletadas em São Miguel do Oeste, SC. Para a produção das mudas foram utilizados tubetes cilíndrico-cônicos de polipropileno, com diâmetro superior interno de $52 \mathrm{~mm}$, altura de $190 \mathrm{~mm}$ e volume de $280 \mathrm{~cm}^{3}$. Os tubetes foram acomodados em bandejas de polipropileno com dimensões de $61,5 \mathrm{~cm}$ x $42,8 \mathrm{~cm}$ e capacidade para 54 tubetes.

O substrato utilizado foi o Mecplant Florestal $3 \AA$, composto produzido a partir da casca de Pinus bioestabilizada e com $55 \%$ de umidade. A densidade (relação peso/volume) sem compactação tem média igual 
a $375 \mathrm{~g}$ litro $^{-1}$. Ao substrato foi adicionado casca de arroz carbonizada, representando $10 \%$ do volume total da mistura, pois apresenta baixa capacidade de retenção de água, drenagem rápida e eficiente, proporcionando boa oxigenação para as raízes (Mello, 2006). Para a adubação de base foi utilizada a formulação $100 \mathrm{~g}-350 \mathrm{~g}-35 \mathrm{~g}$ (uréia, superfosfato simples e cloreto de potássio) para cada 100 litros de substrato.

A lâmina efetiva de irrigação consiste na quantidade de água que deve ser adicionada ao solo para suprir a demanda das plantas num determinado espaço de tempo. Para suprir essa demanda, foram definidas quatro lâminas efetivas de irrigação diárias, convencionadas em 8,10, 12 e $14 \mathrm{~mm}$. A aplicação dos tratamentos foi parcelada, às 10,13 e 16 horas (Tabela 1 ), conforme Lopez (2007), com início ao fim da semeadura.

Tabela 1. Distribuição dos tratamentos e horários para aplicação das lâminas em mudas de aroeira vermelha.

\begin{tabular}{ccccc}
\hline $\begin{array}{c}\text { Horário de } \\
\text { irrigação }\end{array}$ & T1 (mm) & T2 (mm) & T3 (mm) & T4 (mm) \\
\hline 10:00 h & 2 & 2 & 2 & 2 \\
13:00 h & 4 & 4 & 4 & 6 \\
16:00 h & 2 & 4 & 6 & 6 \\
\hline Total & 8 & 10 & 12 & 14 \\
\hline
\end{tabular}

A irrigação foi realizada, de forma individualizada, utilizando copos plásticos confeccionados com o auxílio de uma proveta graduada e aferidos conforme a equação 1:

$\mathrm{Vc}=\frac{\mathrm{mm} \times \mathrm{At}}{1000}$

Onde:

Vc: Volume do copo (mL)

mm: Lâmina de irrigação (mm)

At: Área da circunferência do tubete $\left(\mathrm{mm}^{2}\right)$

O delineamento experimental utilizado foi blocos ao acaso, utilizando três blocos compostos por duas bandejas cada, sendo que a capacidade de cada bandeja foi de 54 tubetes, dos quais eram 24 plantas úteis para cada tratamento e seis espaços vazios entre os tratamentos.

As medições do experimento foram realizadas aos 30 , 60, 90 e 120 dias após aplicação da lâmina de irrigação, sendo a altura da parte aérea (APA), medida com régua milimetrada, da superfície do substrato até o último lançamento de folhas e o diâmetro do colo (DC), medido com paquímetro digital de precisão. A relação APA/D foi calculada ao fim do experimento (120 dias), através da relação entre a altura e o diâmetro do colo.

Após 120 dias foram selecionadas quatro plantas úteis, localizadas no centro da bandeja de forma sistemática. As plantas selecionadas foram retiradas das bandejas e seccionadas na região do coleto separando a parte radicular da parte aérea. A parte radicular foi lavada sobre peneira com malha de $1 \mathrm{~mm}$, visando à retirada do substrato. Posteriormente, as raízes foram colocadas em bandejas de plástico durante 24 horas para a remoção do excesso de água.

As partes aérea e radicular foram acondicionadas separadamente em embalagens de papel, identificadas e secas em estufa, previamente aquecida a $75^{\circ} \mathrm{C}$, onde o material foi mantido até atingir o peso seco constante, em uma balança digital de precisão. Os dados obtidos foram utilizados para o cálculo do índice de qualidade de Dickson, conforme a equação 2:

$$
I Q D=\left(\frac{(P M S P A+P M S R)}{(A P A / D C)+(P M S P A / P M S R)}\right)
$$

Onde:

APA: altura da parte aérea $(\mathrm{cm})$;

D: diâmetro do colo (mm);

PMSPA: peso da matéria seca da parte aérea (g); e

PMSR: peso da matéria seca de raiz (g).

Para a análise de variância foi usado o programa Assistat versão 7.5 Beta, seguido do teste de médias de Tukey, a 5\% de probabilidade de erro.

\section{Resultados e discussão}

As lâminas de irrigação apresentaram respostas estatisticamente diferentes para a relação APA/D e as características morfológicas avaliadas (Tabela 2). Este resultado era esperado, uma vez que a menor lâmina ( 8 $\mathrm{mm}$ ) é cerca de $43 \%$ inferior a maior lâmina (14 mm). Apesar da amplitude das lâminas, o índice de qualidade de Dickson não apresentou diferença estatística entre os tratamentos, segundo o teste de Tukey. 
Tabela 2. Médias dos parâmetros avaliados na produção de mudas de aroeira vermelha, submetidas a diferentes lâminas de irrigação, em Santa Maria, RS.

\begin{tabular}{cccccccc}
\hline $\mathbf{L E}^{*}$ & $\mathbf{A P A}(\mathbf{c m})$ & $\mathbf{D}(\mathbf{m m})$ & $\mathbf{A P A} / \mathbf{D}$ & $\mathbf{M S R}$ & MSPA & MST & IQD \\
\hline 8 & $13,6 \mathrm{c}$ & $2,9 \mathrm{c}$ & $4,7 \mathrm{~b}$ & $1,7 \mathrm{~b}$ & $2,5 \mathrm{~b}$ & $4,2 \mathrm{~b}$ & $0,68 \mathrm{a}$ \\
10 & $20,1 \mathrm{ab}$ & $3,4 \mathrm{a}$ & $5,9 \mathrm{a}$ & $2,5 \mathrm{ab}$ & $4,5 \mathrm{a}$ & $7,0 \mathrm{a}$ & $0,91 \mathrm{a}$ \\
12 & $22,5 \mathrm{a}$ & $3,6 \mathrm{a}$ & $6,2 \mathrm{a}$ & $2,6 \mathrm{a}$ & $4,7 \mathrm{a}$ & $7,3 \mathrm{a}$ & $0,92 \mathrm{a}$ \\
14 & $17,0 \mathrm{bc}$ & $3,3 \mathrm{ab}$ & $5,2 \mathrm{~b}$ & $2,2 \mathrm{ab}$ & $3,3 \mathrm{ab}$ & $5,5 \mathrm{ab}$ & $0,82 \mathrm{a}$ \\
\hline
\end{tabular}

* LE: Lâmina efetiva. APA: Altura de parte aérea. D: Diâmetro do colo. APA/D: relação altura da parte aérea/ diâmetro. MSR: Peso de massa seca de raiz. MSPA: Peso de massa seca de parte aérea. MST: Massa seca total. IQD: Índice de qualidade de Dickson. Letras iguais na coluna indicam que não houve diferença estatística ao nível de $5 \%$ de probabilidade de erro.

Os resultados dos testes de médias demonstraram que os tratamentos 3 e 2 apresentaram maiores valores para todos os parâmetros avaliados, não diferindo entre si. O tratamento que proporcionou pior desempenho das mudas foi o T1, comprovando que a irrigação de $8 \mathrm{~mm}$ diários foi insuficiente para suprir a necessidade fisiológica das mudas.

Lopes et al. (2007), trabalhando com diferentes manejos hídricos, verificaram que o aumento da área foliar e o desenvolvimento morfológico está associado à disponibilidade de água, isto decorrente do uso da água na fotossíntese para a produção de fotoassimilados. Porém, a mesma autora acrescenta que quantidades acima da capacidade de retenção do substrato favorecem a lixiviação de nutrientes prejudicando o desenvolvimento morfológico da planta, fato que pode ter influenciado o desempenho do T4. Gonçalves (1992) ressaltou que plantas em estresse hídrico podem apresentar ineficiência no desenvolvimento morfológico em consequência da morte de células, de tecidos ou órgãos da planta. Corroborando com este autor, durante as medições no T1 foi constado o amarelecimento seguido de queda das folhas, apresentando características típicas de estresse hídrico.

Analisando as características separadamente, constatou-se que a menor média para o diâmetro foi verificada no T1, que também apresentou os menores valores para as demais características avaliadas, indicando a necessidade da espécie por maior lâmina de irrigação, provavelmente, devido a sua característica heliófila e seu rápido desenvolvimento (Carvalho, 1994) e a morfologia da folha. A espécie, por ser pioneira, demanda maior intensidade luminosa, apresentando uma capacidade fotossintética e fisiológica mais ativa, desta forma, demandando maior quantidade de água para incorporar biomassa (Gonçalves et al., 2003). Segundo
Caldeira et al. (2008), mudas de aroeira vermelha devem ser plantadas a campo com no mínimo $2,5 \mathrm{~mm}$ de diâmetro do colo. Com base nos valores observados no presente estudo, todos os tratamentos resultaram em valores adequados.

A relação APA/D, segundo padrão recomendado por Birchler et al. (1998), para espécies florestais deve ser menor que 10, valor observado em todos os tratamentos analisados. Entretanto, Carneiro (1995) salienta que, quanto menor for este valor, maior será a capacidade das mudas de sobreviverem e se estabelecerem.

Para a massa seca da raiz, notou-se que o T3 se destacou, seguido pelo T2 e T4 que não diferiram entre si. O T1 apresentou menor crescimento radicular, possivelmente devido a menor quantidade de água recebida. Segundo Ferreira et al. (1999), o déficit hídrico afeta primeiro as raízes, a partir do qual são desencadeados uma série de efeitos em toda a planta. Carneiro (1995) ressalta sobre a importância das raízes, as quais asseguram maior desenvolvimento às mudas, pois as mesmas estão fortemente associadas às atividades fisiológicas, e são fundamentais para estimar a sobrevivência e o crescimento inicial, em condições de campo.

Sabonaro (2006), trabalhando com composto de lixo urbano e dois níveis de irrigação com espécies nativas (Tabebuia heptaphylla, Cariniana legalis e Schizolobium parahyba), observou que a massa seca da raiz está relacionada diretamente com o desenvolvimento das plantas, pois plantas maiores apresentavam maior massa de raiz (Tabela 2).

A massa seca da parte aérea indica a rusticidade e correlaciona-se diretamente com a sobrevivência e desempenho inicial das mudas após o plantio (Gonçalves, 1992). Resultados similares foram obtidos por Sabonaro (2006), onde foram constadas diferenças 
estatísticas significativas entre as variações nas lâminas de irrigação para a massa seca aérea. A mesma autora acrescenta que quanto maior o crescimento das raízes, maior a parte aérea, tendência comprovada no presente estudo.

Para o índice de qualidade de Dickson (IQD), verificou-se o maior valor para mudas submetidas ao $\mathrm{T} 3$, entretanto, o T4, tratamento com maior quantidade de água, apresentou resultados inferiores ao T2 e T3, indicando que pode ter ocorrido lixiviação de nutrientes. O IQD possibilitou a distinção dos tratamentos mais eficientes para a produção de mudas de aroeira-vermelha, em que associando estes resultados com a relação APA/D é possível confirmar que a melhor lâmina de irrigação ocorre entre $10 \mathrm{~mm}$ e $12 \mathrm{~mm}$.

Sabonaro (2006) relatou que mudas com maior índice de qualidade de Dickson apresentaram maior diâmetro do colo, massa seca da parte aérea, do sistema radicular e total e menores valores da relação altura da parte aérea/diâmetro do colo. De acordo com este estudo, fica evidente essa afirmação, entretanto, a relação altura/diâmetro do coleto não apresentou o mesmo comportamento que o encontrado pela autora. Contudo, Gonçalves (1992) acrescenta que quanto maior o índice de qualidade de Dickson, melhor a qualidade das mudas.

Segundo Fonseca et al. (2002), o índice de qualidade de Dickson é um bom indicador da qualidade das mudas, pois no seu cálculo são considerados robustez e equilíbrio da distribuição de biomassa na muda, ponderando os resultados de várias características importantes empregadas para avaliação da qualidade. Entretanto, neste estudo, o coeficiente de qualidade de Dickson não foi um bom indicador, pois não diferenciou os tratamentos, apesar de apresentar amplitude considerável entre os tratamentos.

De acordo com a Tabela 2, pode-se indicar como variáveis eficientes para a classificação da qualidade de mudas de Schinus terebinthifolius a altura, o diâmetro, a relação APA/D e a massa seca total, os quais apresentaram maiores amplitudes entre as médias dos tratamentos avaliados. Para a distinção entre os tratamentos com $10 \mathrm{~mm}$ e $12 \mathrm{~mm}$, respectivamente T2 e T3, foi construído o gráfico do crescimento das mudas no tempo (Figura 2).
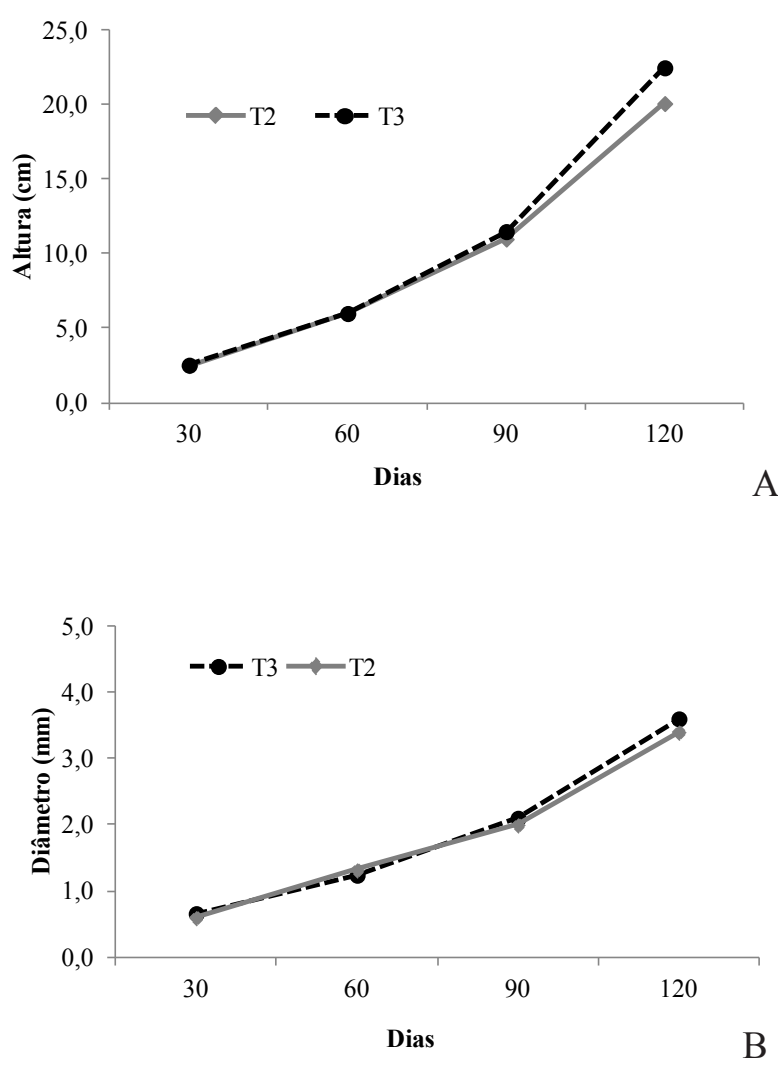

Figura 2. Crescimento das mudas de aroeira vermelha, submetidas a diferentes laminas de irrigação.

Analisando de modo relacionado as Figuras 1 e 2, nota-se que os tratamentos T2 $(11,3 \mathrm{~cm})$ e T3 $(11,9 \mathrm{~cm})$ apresentaram resultados semelhantes. Após a terceira medição (novembro) ocorreu aumento da temperatura, seguida da queda de umidade que contribuiu para a perda por transpiração das plantas, culminando com aumento da necessidade de água. Neste contexto, a lâmina de irrigação de $12 \mathrm{~mm}$ promoveu desenvolvimento ligeiramente melhor que a de $10 \mathrm{~mm}$ para as mudas de aroeira vermelha, porém não o suficiente para caracterizar diferença entre os tratamentos.

Lopes et al. (2007), estudando a qualidade de mudas de eucalipto produzidas com diferentes lâminas de irrigação diária $(6,8,10,12$ e $14 \mathrm{~mm})$ e dois tipos de substratos, concluiu que as lâminas de irrigação de 
$12 \mathrm{~mm}$ e $14 \mathrm{~mm}$ foram as que mais contribuíram para o desenvolvimento morfológico das mudas de eucalipto. No presente estudo identificou-se que a aroeira-vermelha possui necessidade hídrica menor que a do eucalipto, pois foi identificada a lâmina ideal entre $10 \mathrm{mme} 12 \mathrm{~mm}$, fato este que pode ser explicado pela alta taxa de crescimento aliado ao uso da água para a produção de fotoassimilados para as mudas de eucalipto (Pereira et al., 2006) e as diferentes épocas e condições climáticas da realização dos dois estudos.

\section{Conclusão}

De acordo com a análise estatística das médias dos tratamentos, recomenda-se que a lâmina de irrigação a ser utilizada seja de $10 \mathrm{~mm}$ diariamente, para um desempenho satisfatório, aliado ao uso racional de água para a produção de mudas de Schinus terebinthifolius Raddi.

\section{Referências}

AUGUSTO, D. C. C.; GUERRINI, I. A.; ENGEL, V. L.; ROUSSEAU, G. X. Utilização de águas residuárias provenientes do tratamento biológico de esgotos domésticos na produção de mudas de Eucalyptus grandis Hill. ex. maiden. Revista Árvore, Viçosa, MG, v. 31, n. 4, p. 745-751, 2007.

BIRCHLER, T.; ROSE, R. W.; ROYO, A.; PARDOS, M. La planta ideal: revision del concepto, parametros definitorios e implementaction practica. Investigacion Agraria, Sistemas y Recursos Forestales, Madrid, v. 7, n. 1/2, p. 109-121, 1998.

BRASIL. Lei n. 6.381, de dezembro de 2005. Dispõe sobre a Política Nacional de Irrigação e dá outras providências. Brasília, DF, 13 dez. 2005. Disponível em: < http://www.camara.gov.br/ sileg/integras/364296.pdf>. Acesso em: 8 ago. 2008.

CALDEIRA, M. V. W.; ROSA, G. N. da; FENILLI, T. A. B.; HARBS, R. M. P. Composto orgânico na produção de mudas de aroeira-vermelha. Scientia Agraria, Curitiba, v. 9, n. 1, p. 27-33, 2008.

CARNEIRO, J. G. A. Produção e controle de qualidade de mudas florestais. Curitiba, UFPR: FUPEF: UENF, 1995.
CARVALHO, P. E. R. Espécies florestais brasileiras: recomendações silviculturais, potencialidades e uso da madeira. Colombo: EMBRAPA-CNPF; Brasília, DF: EMBRAPA-SPI, 1994. $640 \mathrm{p}$.

FERREIRA, C. A. G.; DAVIDE, A. C.; CARVALHO, L. R. de. Relações hídricas em mudas de Eucalyptus citriodora Hook., cm Tubetes, Aclimatadas por Tratamentos Hídricos. Revista Cerne, Lavras, MG, v. 5, n. 2, p. 95-104, 1999.

FONSECA, E. P.; VALERI, S. V.; MIGLIORANZA, E.; FONSECA, N. A. N.; COUTO, L. Padrão de qualidade de mudas de Trema micrantha (L.) Blume, produzidas sob diferentes períodos de sombreamento. Revista Árvore, Viçosa, MG, v. 26, n. 4, p. 515-523, 2002.

GONÇALVES, M. R. Crescimento, acúmulo de nutriente e temperatura de copa em cinco espécies de Eucalyptus ssp. sob dois regimes hídricos. 1992. 84 f. Dissertação (Mestrado em Silvicultura) - Universidade Federal de Viçosa, Viçosa, MG.

GONÇALVES, J. L. M.; NOGUEIRA JUNIOR, L. R.; DUCATTI, F. 2003. Recuperação de solos degradados. p. 129-133. In: KAGEYAMA, P. Y.; OLIVEIRA, R. E.; MORAES, L. F. D; ENGEL, V. L. E.; GANDARA, F. B. Restauração ecológica de ecossistemas naturais. Botucatu: Fundação de Estudos e Pesquisas Agricolas e Florestais, 2003.

LOPES, J. L. W.; GUERRINI, I. A.; SAAD, J. C. C. Qualidade de mudas de eucalipto produzidas sob diferentes lâminas de irrigação e dois tipos de substrato. Revista Árvore, Viçosa, MG, v. 31, n. 5, p. 835-843, 2007.

LORENZI, H. Árvores brasileiras: manual de identificação e cultivo de plantas arbóreas nativas do Brasil. Nova Odessa: Plantarum, 1992. $352 \mathrm{p}$.

MELLO, R. P. Consumo de água do lírio asiático em vaso com diferentes substratos. 2006. 74 f. Dissertação (Mestrado em Engenharia Agrícola) - Universidade Federal de Santa Maria, Santa Maria, RS.

PEREIRA, M. R. R.; KLARL, A. E.; SILVA, M. R. da; SOUZA, R. A. de; FONSECA, N. R. Comportamento fisiológico e morfológico de clones de Eucalyptus urograndis submetidos a diferentes níveis de água no solo. Revista Irriga, Botucatu, v. 11, n. 4, p. 518-531, 2006.

SABONARO, D. Z. Utilização de composto de lixo urbano na produção de mudas de espécies arbóreas. 2006. $83 \mathrm{f}$. Dissertação (Mestrado em Agronomia) - Faculdade de Ciências Agrárias e Veterinárias, Universidade Estadual Paulista, Jaboticabal. 